\title{
MULTIVARIATE ANALYSIS OF PHENOTYPIC PLASTICITY IN CARIBBEAN COLUMBELLA SPECIES (NEOGASTROPODA: COLUMBELLIDAE).
}

DEMAINTENON, Marta J., Department of Integrative Biology, university of California, Berkeley, California, 94720-3140.

Four to five nominal species of Columbella are present in the Caribbean from the Late Miocene to the Recent, part of a monophyletic tropical American clade. These species provide an interesting problem for biogeographic and evolutionary studies; they are geologically long-lasting and geographically widespread, but have nonplanktic development, based on protoconch comparisons with living taxa in the same clade. They also exhibit a high degree of phenotypic plasticity throughout the spatial and temporal ranges of the species. These characteristics suggest the potential existence of one or more poorly differentiated sibling species within this clade, and have inspired the generation of numerous specific and varietal names, few of which are considered distinct enough to be used in current classifications.

One of the ways to differentiate sibling species, particularly for fossil taxa where only shell characters are preserved, is multivariate morphometric analysis. The objective of this study is to use multivariate analyses of conchological characteristics in the Caribbean Columbella species to differentiate discrete morphological variations. This analysis, including fossils, will delimit morphological species in time and space, as well as the characters that diagnose them. It will also facilitate examination of the patterns of morphological change through time, by which these species became differentiated. 